\title{
Exogenous Acylated Ghrelin Promotes but Un-acylated Ghrelin Prevents Hepatic Steatosis by Modulating Peripheral Insulin Resistance and Hepatic Oxidative and Endoplasmic Reticulum Stress
}

\author{
Samah Alharbi i*, Refaat A. Eid ${ }^{2}$
}

'Department of Physiology, Faculty of Medicine, Umm Al-Qura University, Makkah, Saudi Arabia.

Electron Microscope Unit, College of Medicine and Medical Science, King Khalid University, Abha, Saudi Arabia.

*Correspondence to: Samah Alharbi (Email: saaharbi@uqu.edu.sa).

(Submitted: 03 March 2021 - Revised version received: 22 March 2021 - Accepted: 15 April 2021 - Published online: 26 June 2021)

\begin{abstract}
Objectives: This study tested the effects of acylated (AG and un-acylated ghrelin (UAG) on hepatic lipid synthesis and insulin resistance (IR) from prospective to their effect on endoplasmic reticulum stress and investigated the possible underlying mechanisms.

Methods: Healthy rats were divided as 4 groups ( $n=12 /$ each) as control, control + AG, control + UAG, and control + AG + UAG (1:1). GA or UAG were given subcutaneously ( $200 \mathrm{ng} / \mathrm{kg} / \mathrm{each}$ ) for 8 weeks.

Results: AG increased fasting levels of glucose and insulin resistance, increased hepatic glucose production, and impaired glucose and insulin tolerance. Besides, it increased serum levels of free fatty acids (FFAs), enhanced serum and hepatic levels of triglycerides and cholesterol, and increased lipid deposition in the livers of rats. Concomitantly, it stimulated the mRNA levels of SREBP1/2, fatty acid synthase, and protein levels of all arms of ER stress including Xbp-1, CHOP, ATF-6, and p-elF2a, thus activating lipid synthesis and ER stress. It also reduced protein levels of p-IRS (Tyr $\left.{ }^{612}\right)$, p-Akt (Ser $\left.{ }^{307}\right)$, and increased levels of ROS, TNF-a, IL-6, and protein levels of cleaved caspase-12, p-IRS $\left(\mathrm{Ser}^{307}\right)$, and $\mathrm{p}-\mathrm{JNK}\left(\mathrm{The}^{183} / \mathrm{Tyr}^{186}\right)$ in rats' livers. Administration of UAG alone or in combination with AG produced contradictory effects. However, both AG and UAG significantly increased mRNA levels of AMPK and PPARa suggesting FAs oxidation.

Conclusion: AG induces hepatic steatosis and suppresses hepatic insulin signaling mainly by inducing peripheral IR that is associated with hepatic oxidative stress, inflammation, and ER stress. However, UAG alone or in combination exerts opposite effects.

Keywords: Ghrelin, Acylated, Insulin Resistance, Steatosis, Liver, Endoplasmic Reticulum, Oxidative Stress.
\end{abstract}

\section{Introduction}

Non-alcoholic fatty liver disease (NAFLD) is one of the most common chronic liver disease that is linked with obesity, diabetes mellitus (DM), insulin resistance (IR), and other metabolic disorders. ${ }^{1-3}$ It develops by over-accumulation of triglyceride (TGs) in the liver and its complications range from simple steatosis to non-alcoholic steatohepatitis (NASH). ${ }^{2-4}$ Up-to-date, the underlying mechanisms involved in the pathogenesis of NAFLD are still not fully understood with oxidative stress being the key player. ${ }^{1-3}$

Currently, the emerging role of the endoplasmic reticulum (ER) stress in the development and progression of NAFLD is well-established. ${ }^{5}$ The ER is an essential cellular organelle that is found in large quantities in the liver of mammals and plays an essential role in the process of protein and lipid synthesis. ${ }^{5}$ However, the accumulation of unfolded proteins in the ER during the high metabolic activity triggers unfolded protein response (UPR) and ER stress via the activation of different transmembrane signal transducers. ${ }^{5}$ Although the initial activation of the UPR is a protective mechanism that suppresses protein synthesis and enhances cell survival, the unresolved sustained UPR and ER stress is associated with hepatic lipid accumulation, IR, steatosis, and hepatocytes apoptosis. ${ }^{6}$ The precise mechanisms behind this are well-demonstrated in excellent reviews and studies. ${ }^{5,7-9}$ Indeed, the role of ER stress in the development of hepatic steatosis and IR has been demonstrated in several conditions including obesity, ${ }^{7}$ alcoholism, ${ }^{8}$ viral hepatitis, ${ }^{9}$ and NAFLD. ${ }^{5,12-17}$ However, suppressing ER by pharmacological approaches or by weight loos reduced hepatic steatosis and improved hepatic insulin signaling. 7 , 15, 18-20
On the other hand, the currently available data suggest that NAFLD is no longer considered an exclusively hepatic disorder. In this setting, the gut-liver axis has been recently shown to play a crucial role in the regulation of hepatic lipogenesis and has been identified as a key player in the development/prevention of NAFLD. ${ }^{3,21-27}$ Ghrelin is the major gut hormone released from the stomach and the gut, and to a lesser extent from other peripheral tissues. ${ }^{28}$ In the circulation, ghrelin circulates in two forms, a common dominant form $(>90 \%)$ named acylated ghrelin (AG, n-octanoylated at $\mathrm{Ser}^{3}$ ) or des-acyl (unacylated) ghrelin (UAG) without this post-translational modification. ${ }^{28}$ In mammals, such acylation is mediated by the activation of ghrelin-ghrelin O-acyltransferase (GOAT) enzyme, which is widely distributed in the stomach and other peripheral tissues including the adrenal cortex, breast, and colon. ${ }^{3,29}$ It is currently well-accepted that AG acts peripherally by activating its receptors, secretagogue receptor type la (GHS-R1a) where the effects exerted by UAG are through other unidentified receptors. ${ }^{3}$

Studies on the effect of the two forms of ghrelin on NAFLD progression revealed contradictory effects where AG induces but UAG inhibits hepatic steatosis. Indeed, the direct effect of AG on the liver was stimulating hepatic lipogenesis and inducing hepatic steatosis, IR and apoptosis through different pathways including: 1) activation of fatty acids (FAs) synthesis-related transcription factors and genes (i.e. sterol regulatory element-binding protein-1c (SREBP-1c) AcetylCoA carboxylase 1 (ACC-1), fatty acid synthase (FAS), 2) Activation of P53, mammalian target of rapamycin (mTOR), peroxisome proliferator-activated receptor-gamma (PPAR $\gamma$ ), 
and $\mathrm{C}$ (PKC) signalling pathways, and 3) inhibition of the mitochondria fatty acids (FAs) oxidation by suppressing the activity and levels $5^{\prime}$ AMP-activated protein kinase (AMPK), carnitine palmitoyltransferase I (CPT-1), and PPRAa. ${ }^{25,30-35}$ On the other hand, the majority of studies have shown that UAG administration is associated with suppressing hepatic lipogenesis mainly due to stimulating FAs oxidation. ${ }^{35-37}$ Opposing these data, a single study has shown that exogenous chronic administration of AG in combination with HFD for 8 weeks limited liver triglyceride content, oxidative stress, and inflammation in a rat model of HFD-induced obesity. ${ }^{24}$

Until now, the effect of AG and DAG on hepatic lipogenesis from perspective of their effect of UPR arms and ER stress was never tested yet which was worthy for us. Therefore, in this study, we aimed to investigate the effect of chronic individual or combined administration of AG and UGA on hepatic steatosis and IR in healthy rats with respect to their effects on UPR and markers of ER stress.

\section{Materials and Methods}

\section{Animals}

All procedures of the current study were approved by the animal ethical committee at Umm Al-Qura University (UQU), Makkah, Saudi Arabia (IRB \# HAPO-02-2019-03-307) which their regulations follow the animal ethics and guidelines established by the US National Institutes of Health (NIH publication No. 85-23, revised 1996). Adult male Sprague-Dawley rats (120-140 g, 7-8 weeks) were supplied by the animal house at King Khalid University, Abha, KSA. During the experimental procedure, all rats were always maintained under the stable condition of a controlled temperature $\left(22 \pm 1^{\circ} \mathrm{C}\right)$, humidity (40-65\%), and light/dark cycle (12 hours/each) and had free access to their drinking water and diet.

\section{Experimental design}

Rats were divided into 4 groups $(\mathrm{n}=12 /$ each) as follows: 1$)$ LFD control group: received a daily dose normal saline, 2) Control +AG-treated group: received a daily dose of AG (200 ng/kg) (Cat. No. G8903, Sigma, Aldrich, UK), 3) Control + UAG-treated group: received a daily dose of UAG (200 ng/kg) (Cat No. 2951, Sigma, Aldrich, UK), and 4) Control + AG + UAG-treated group: received a concomitant daily dose of both AG and UAG (200 ng/ml/each). The vehicle, AG and UAG were administered to rats subcutaneously (s.c) every day for consecutive 8 weeks. The dose selections of AG and DAG were adopted from the study of Dallak, ${ }^{27}$ who showed diabetogenic and lipogenic effects of AG that was resolved by an equal dose of UAG, effects that were independent of food intake.

\section{Oral glucose tolerance test (OGTT)}

By the end of the experimental procedure, all rats/groups were fasted for $12 \mathrm{~h}$ and received an oral dose of glucose $(2 \mathrm{~g} / \mathrm{kg})$. $^{38}$ Then, blood samples $(300 \mu \mathrm{l})$ were withdrawn from all rats into K2EDTA microtubes (BD microtainers, Cat. No. 363706, $\mathrm{BD}, \mathrm{USA}$ ) at $0.0,0.0,15,30,60$ and 120 minutes at or post-glucose administration. All blood samples were centrifuged at $3000 x g$ for 10 minutes to collect plasma. Plasma samples were stored at $-20^{\circ} \mathrm{C}$ for later determination of glucose and insulin levels using rat's special colorimetric and ELISA kits purchased from (Cat. No. 81693 and 90010, ChrystalChem, IL, USA respectively). Hepatic insulin resistance (IR) was determined for each rats using the homeostasis model assessment of insulin resistance index $(\mathrm{HOMA}-\mathrm{IRI})([\mathrm{FPG}(\mathrm{mg} / \mathrm{dl}) \times$ Fasting IRI(ng/ml)]/405).

\section{Serum and tissue collection}

Directly after OGTT, rats $(n=6)$ were fasted for 4 hours and then anesthetized with pentobarbital sodium $(60 \mathrm{mg} / \mathrm{kg})$. Blood samples $(1 \mathrm{ml})$ were withdrawn from the rat's hearts directly and centrifuges at $3000 x g$ for $10 \mathrm{~min}$ to prepare sera which were stored at $-20^{\circ} \mathrm{C}$ for determination of TGs and $\mathrm{CHOL}$ levels. Then, the liver of each rat was rapidly removed on ice, washed with $0.01 \mathrm{M}$ ice cold-phosphate buffer $(\mathrm{pH}=$ 7.4 ), and cut into small pieces. Some liver samples were snapfrozen in liquid nitrogen and stored at $-80^{\circ} \mathrm{C}$ for further biochemical and molecular analysis. Other parts of livers were placed in $10 \%$ buffered formalin and processed for histopathological evaluation. Besides, gastrocnemius muscle samples were collected from all rats for determination of glycogen content.

\section{Hepatic lipid extraction}

Hepatic lipid extraction for the measurements of TGs and cholesterol (CHOL) levels were prepared according to the method of Folch et al. (1957). To prepare total cell homogenates, parts of frozen livers $(30 \mathrm{mg})$ were homogenized, individually, in $0.5 \mathrm{ml}$ ice-cold PBS (pH 7.4) containing $10 \mu$ l protease inhibitor (Cat. No. P8340 Sigma-Aldrich, MO, USA), centrifuged at $10000 \mathrm{xg}$ for $10 \mathrm{~min}$ to collect supernatants.

\section{Biochemical analysis in the serum and liver homogenates}

Serum and hepatic levels of TGs were measured using a commercially available kit (Cat. No. MBS726298 and MBS168179, MyBioSource, CA, USA respectively). Hepatic and muscle glycogen content was determined using a glycogen assay colorimetric kit (Cat. No. KA8061, Abnova, USA). Hepatic levels of ROS were measured using an assay kit (Cat. No. STA-347, Cell Biolabs, Inc. San Diego, CA). Hepatic levels of reduced and oxidized glutathione (GSH) were determined using a rat's colorimetric assay determination kit (Cat. No. Ab138881/ Abcam, UK). Hepatic levels of malondialdehyde (MDA) were measured using a colorimetric determination kit (Cat. No. ab118970/ Abcam, UK). Serum and hepatic levels of free fatty acids (FFAs) levels were assayed using a colorimetric kit (E1001, Applygen Technologies Inc., Beijing, China). Hepatic levels of tumour necrosis factor- $\alpha$ TNF- $\alpha$ and interleukin- 6 (IL-6) were measured using ELISA kits (Cat. No. MBS267737 and MBS355410 MyBioSource, USA, respectively).

\section{Isolated liver preparations and insulin sensitivity}

The inhibition of insulin on glucagon-induced glucose output in all experimental groups (6 rats/group) was studied in freshly isolated perfused livers as previously described by others. ${ }^{39}$ In brief, after stabilization of the liver, bovine glucagon (55.4 pg in $50 \mathrm{ml}$ perfusion buffer) (LT1504; LifeTein, LLC, NJ, USA) was perfused for 20 minutes followed by perfusion of another buffer containing glucagon + insulin $(100 \mu \mathrm{U})$ for the next 15 minutes. Perfusion rate of hormones was carried out at a constant flow rate of $0.17 \mathrm{ml} / \mathrm{minute}$ to achieve portal concentrations of glucagon and insulin of $100 \mathrm{pg} / \mathrm{ml}$ and $100 \mu \mathrm{U}$, 
respectively. The perfusate was collected from the suprahepatic inferior vena cava every five minutes and then used for biochemical analysis of glucose levels using the same glucose kit used to measure plasma glucose. The glucose production rate was presented as $\mathrm{mg} / \mathrm{min} / \mathrm{g}$ liver weight for every 10 minutes of hormone perfusion. The integrated insulin responses were expressed as glucose production rate during the last 10 minutes divided by glucose production rate during the first 10 minutes of the hormone perfusion protocol. During the perfusion, the liver was always checked by gross appearance and color. At the end of the experimental procedure, the liver was removed, weighed, and stored at $-80^{\circ} \mathrm{C}$ for hepatic glycogen level.

\section{Real-time PCR}

Primers used to study mRNA levels of SREBP-1c, PPRAa fatty acid synthase, SREBP1/2 are shown in Table 1. Total RNA was extracted from frozen livers ( $30 \mathrm{mg} / \mathrm{sample}$ ) using an RNeasy Mini Kit (Qiagen, Victoria, Australia). Superscript II reverse transcriptase and oligo (dT) (Thermo Fisher, MA, USA) was used to synthesize the single-stranded cDNA. qPCR runs were performed in a CFX96 real-time PCR system (Bio-Rad, CA, USA) using Ssofast Evergreen Supermix (Bio-Rad, Montreal, Canada). PCR components were $10 \mu \mathrm{l}$ Ssofast Evergreen Supermix, $2 \mu \mathrm{l}$ diluted cDNA (500 ng/ $\mu \mathrm{l}), 0.4 \mu \mathrm{l}$ of $10 \mu \mathrm{M}$ forward primer $(200 \mathrm{~nm} /$ reaction), $0.4 \mu \mathrm{l}$ of $10 \mu \mathrm{M}$ reverse primers $(200 \mathrm{~nm} /$ reaction $\mathrm{n})$, and $6.2 \mu$ of nuclease-free water. All reaction was run as an initial heating step $\left(1 \mathrm{cycle} / 95^{\circ} \mathrm{C} / 30\right.$ $\mathrm{sec})$, a denaturation step $\left(95^{\circ} \mathrm{C} / 5 \mathrm{sec}\right)$, annealing/extension $\left(60^{\circ} \mathrm{C} / 30 \mathrm{sec}\right)$ (each of 34 cycles), and a final melting step $\left(1 \mathrm{cycle} / 95^{\circ} \mathrm{C} / 1 \mathrm{sec}\right)$. Levels of mRNA of each gene were quantified by the associated software using the ${ }^{\Delta \Delta} \mathrm{CT}$ method. Wells with no template DNA served as a negative control. All procedures were conducted according to the manufacturer's instructions and will be done for 6 samples/groups.

\section{Western blotting}

Total proteins were extracted from frozen livers (40 mg) after homogenization in Radioimmunoprecipitation assay (RIPA) buffer $(0.5 \%$ sodium deoxycholate, $0.1 \%$ SDS, $150 \mathrm{mM} \mathrm{NaCl}$, $1.0 \% \mathrm{NP}-40,50 \mathrm{mM}$ Tris ( $\mathrm{pH}$ 8.0) and supplied with a protease inhibitor (Sigma-Aldrich, St. Louis, MO, USA). Protein levels in all samples were measured using a Pierce BCA Protein Assay Kit (Cat. No. 23225, ThermoFisher Scientific). Equal protein samples $(40 \mu \mathrm{g})$ were separated on an $8-12 \%$ gradient SDS-PAGE gel, transferred nitrocellulose membrane, and then blotted with primary antibodies Table 2. Membranes were then blotted with an HRP-conjugated secondary antibody. All washings and antibodies dilution were done in TBS buffer with $0.1 \%$ Tween 20 (TBST). Each membrane was stripped up to 4 times maximum using Restore ${ }^{\mathrm{Tm}}$ pLUS stripping buffer (Thermo Fisher). Bands will be visualized and their intensities will be evaluated using chemiluminescence (Pierce ECL reagents, Thermo Fisher, USA, Piscataway, NJ) and C-Di Git blot scanner (LI-COR, USA). Data were analyzed for at least 3 samples/groups.

\section{Statistical analysis}

Statistical analyses for all measured parameters will be using Graph Pad Prism statistical software package (version 6). Differences among the experimental groups were assessed by one-way ANOVA, followed by Tukey's test. Results of OGTT and glucose production in the isolated liver preparations were analysed using the same software but with 2-way with repeated measures. Data will be presented as means pulse standard deviation (mean $\pm \mathrm{SD}$ ). Values will be considered significantly different when $P<0.05$.

\section{Results}

\section{Metabolic parameters and OGTT}

There were no changes in food intake between all experimental groups of rats. AG-treated rats had higher fasting plasma glucose and insulin levels, as well as HOMA-IRI but had lower hepatic and muscle glycogen content as compared to control rats (Fig. 1, A-F). They also showed an increase in the levels of fasting plasma glucose and insulin at all analysis intervals after the OGTT (Fig. 2, A-D). However, with stable fasting insulin levels and HOMA-IRI, UAG-treated rats showed a significant decrease in fasting plasma glucose levels, and their livers and muscles had higher glycogen content as compared to control rats (Fig. 1, A-F). Besides, the administration of UAG to rats significantly lowered blood glucose and insulin levels between 30-120 minutes of the OGTT (Fig. 2, A-D). On the other hand, co-administration of UAG to AG-treated rats attenuated all the above-mentioned effects exerted by AG (Figs. 1\&2).

\begin{tabular}{|c|c|c|c|}
\hline Gene & Primers & $\begin{array}{l}\text { GenBank } \\
\text { accession }\end{array}$ & $\begin{array}{l}\text { Product } \\
\text { length }\end{array}$ \\
\hline SREBP-1C & $\begin{array}{l}\text { F:5'-GGAGCCATGGATTGCACATT-3' } \\
\text { R:5'- AGGAAGGCTTCCAGAGAGGA-3' }\end{array}$ & AF286470.2 & 191 \\
\hline SREBP-2 & $\begin{array}{l}\text { F:5'-CTGACCACAATGCCGGTAAT-3' } \\
\text { R:5'-CTTGTGCATCTTGGCATCTG-3' }\end{array}$ & NM_001033694.1 & 204 \\
\hline FAS & $\begin{array}{l}\text { F:5'-AGGTGCTAGAGGCCCTGCTA-3' } \\
\text { R:5'-GTGCACAGACACCTTCCCAT-3' }\end{array}$ & X62888.1 & 281 \\
\hline PPAR-a & $\begin{array}{l}\text { F:5'-TCACACAATGCAATCCGTTT-3' } \\
\text { R:5'-GGCCTTGACCTTGTTCATGT-3' }\end{array}$ & NM_013196.1 & 119 \\
\hline AMPK-a1 & $\begin{array}{l}\text { F:5'-TGTGACAAGCACATT TTCCAA-3' } \\
\text { R:5'-CCGATCTCTGTGGAGTAG CAG -3' }\end{array}$ & NM_0191 42 & 131 \\
\hline 18sRNA & $\begin{array}{l}\text { F:5'-GGATCCATTGGAGGGCAAGT-3' } \\
\text { R:5'-ACGAGCTTTTTAACTGCAGCAA-3' }\end{array}$ & NM_017008.4 & 150 \\
\hline
\end{tabular}




\begin{tabular}{llll}
\hline \multicolumn{4}{l}{ Table 2. Characteristics of primary antibodies used in western blotting analysis } \\
\hline Antibody & Cat. No. & MW (kDa) & Manufacturer \\
\hline Xbp-1 & sc-8015 & $29: 1: 250$ & Santa Cruze Biotechnology \\
GADD 153 (CHOP-10) & sc-7351 & $39: 1: 1000$ & Santa Cruze Biotechnology \\
ATF-6a & sc-166659 & $90: 1000$ & Santa Cruze Biotechnology \\
(p-elF2a) (Ser $\left.{ }^{51}\right)$ & 9721 & $38: 1: 1000$ & Cell Signaling Technology \\
pro and cleaved caspase 12 & $2202 a$ & $44 / 55,1: 1000$ & Cell Signaling Technology \\
JNK & sc-7345 & $46 / 54: 1: 1000$ & Santa Cruze Biotechnology \\
p-JNK (Thr ${ }^{183}$ and Tyr $\left.{ }^{185}\right)$ & sc-6254 & $46 / 54: 1: 1000$ & Santa Cruze Biotechnology \\
Akt1 & sc-5298 & $62,1: 1000$ & Santa Cruze Biotechnology \\
p-Akt (Ser $\left.{ }^{473}\right)$ & sc-514032 & $52.1: 500$ & Santa Cruze Biotechnology \\
p-IRS-1/2 (Tyr $\left.{ }^{612}\right)$ & Sc-17195 & $170,1: 500$ & Cell Signaling Technology \\
p-IRS-1 (Ser $\left.{ }^{307}\right)$ & 2381 & $180,1: 500$ & Cell Signaling Technology \\
IRS-1 & 2382 & $180,1: 1000$ & Cell Signaling Technology \\
B-actin & 4970 & $45,1: 2000$ & Cell Signaling Technology, \\
\hline
\end{tabular}

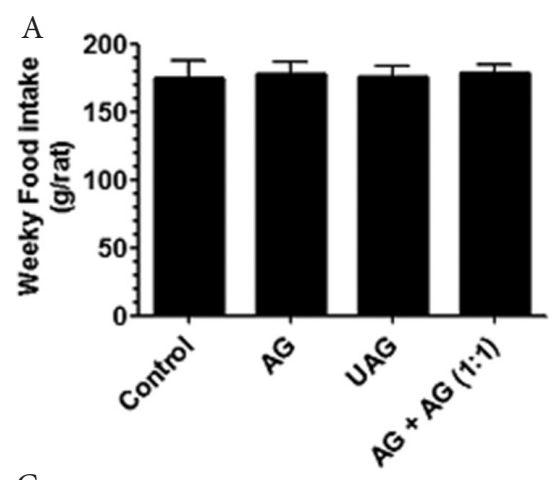

B

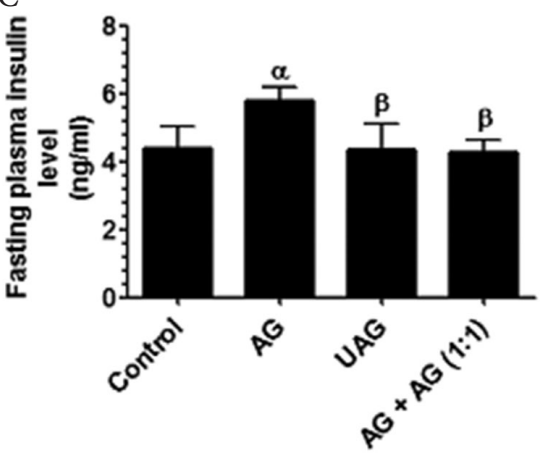

$\mathrm{D}$

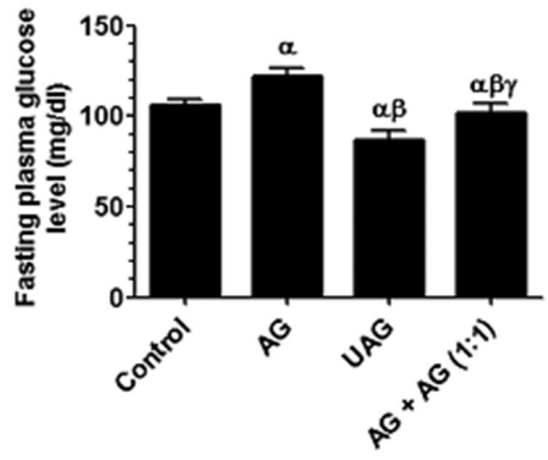

E

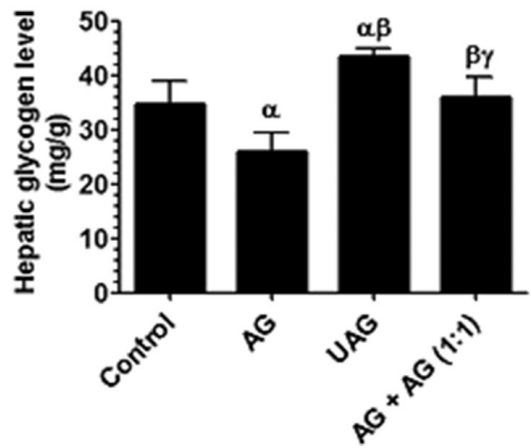

$\mathrm{F}$
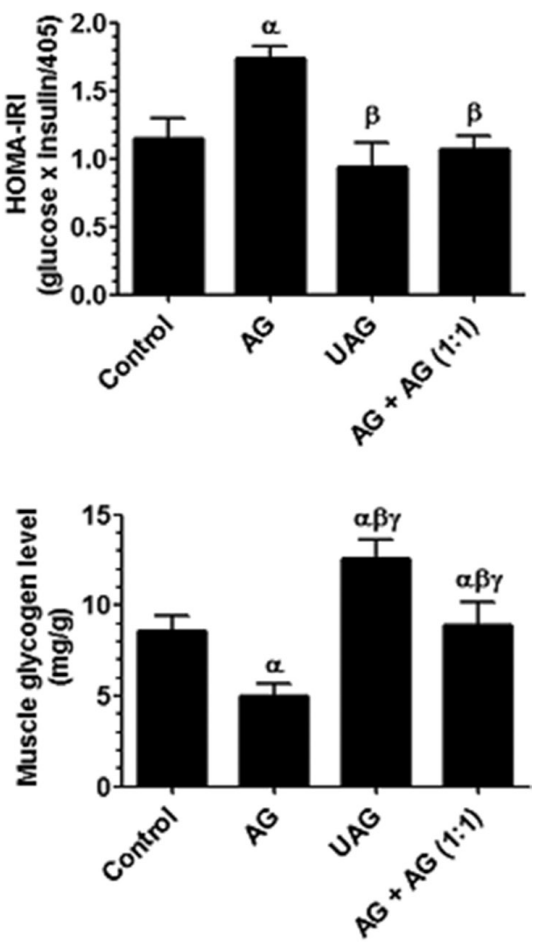

Fig. 1 Metabolic parameters in the all experimental groups. Data are presented as mean \pm SD in 6 rats/ group. ${ }^{a}:$ vs. control rats, ${ }^{\beta}$ : vs. AG-treated rats, and ${ }^{v}$ : vs. UAG-treated rats. AG: acylated ghrelin. UAG: unacylated ghrelin. 
A

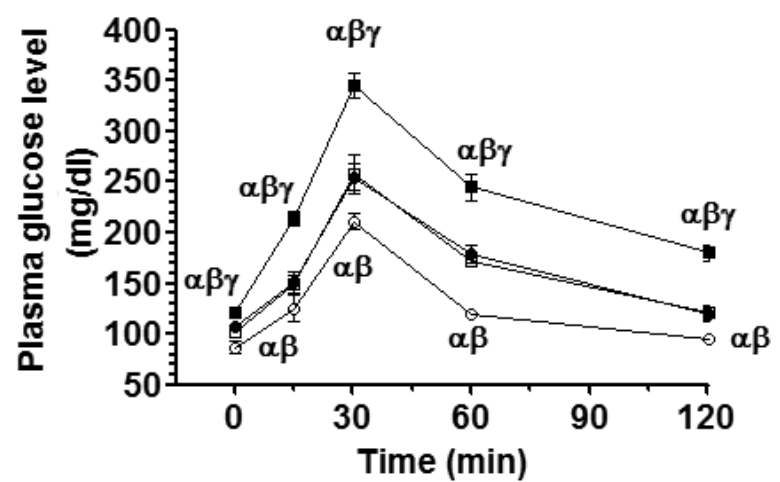

C

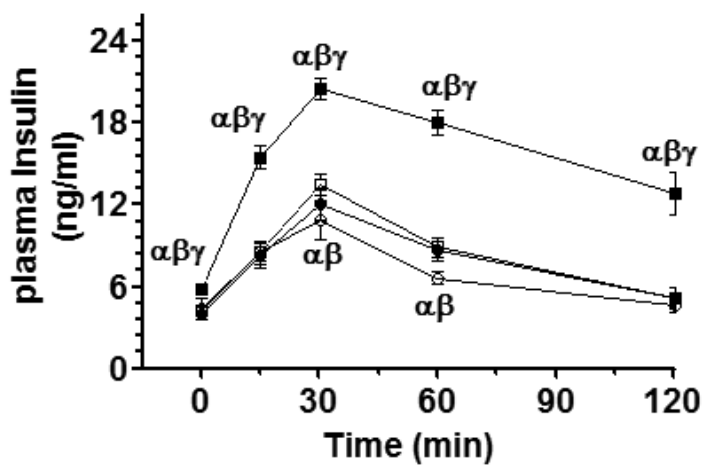

$\mathrm{B}$

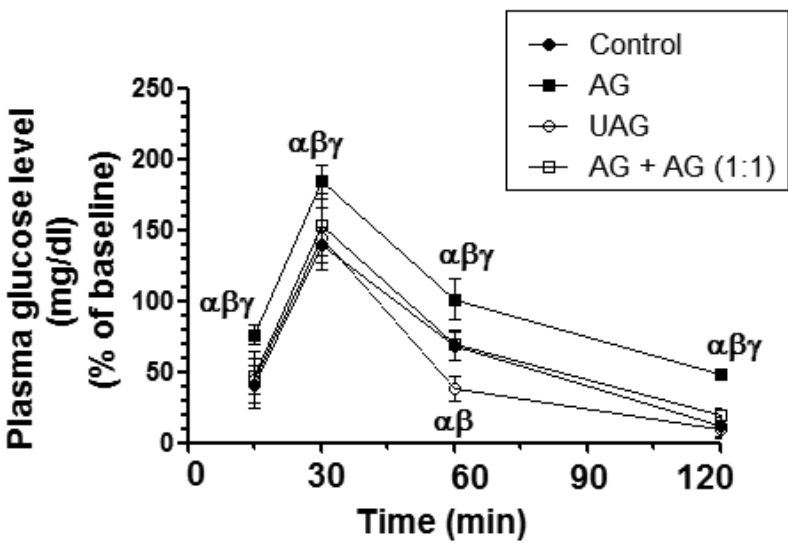

D

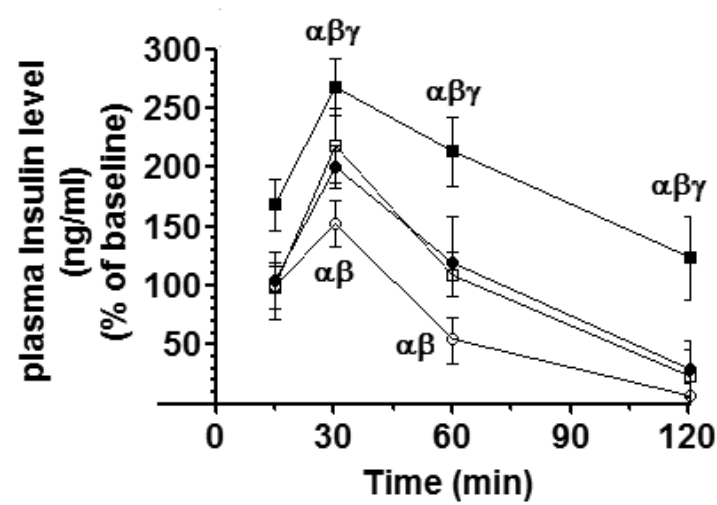

Fig. 2 Outputs of the oral glucose tolerant test (OGTT) in all experimental groups. Data are presented as mean \pm SD in 6 rats/group. ${ }^{a}$ : vs. control rats, $\beta^{\beta}$ : vs. AG-treated rats, and ${ }^{\text {}: ~ v s . ~ U A G-t r e a t e d ~ r a t s . ~ A G: ~ a c y l a t e d ~ g h r e l i n . ~ U A G: ~ u n a c y l a t e d ~ g h r e l i n . ~}$

\section{Alterations in glucose production and glycogen content in isolated liver preparation}

Livers isolated from AG-treated rats showed glucose production during the first 20 minutes after being challenged with glucagon alone (Fig. 3, A\&B). However, glucose levels remained significantly higher than all other groups during the last 15 minutes when they were perfused with a solution containing insulin and glucagon, indicating IR (Fig. 3, A\&B). Consequently, they had the highest integration glucose production rate and had the lowest glycogen content (Fig. 3, $\mathrm{C} \& \mathrm{D})$. On the other hand, glucose production during glucagon perfusion alone or with perfusion of insulin and glucagon, as well as glucose production rate was significantly decreased with a concomitant increase in glycogen content was seen in isolated livers obtained from UAG treated rats (Fig. 3, A-D). However, normal glucose response, glucose production, and glycogen levels were observed in the isolated livers of AG + UAG-treated rats (Fig. 3, A-D).

\section{Hepatic and serum lipids profile and liver histology in all groups of rats}

Significantly higher serum and hepatic levels of TG, CHOL, and FFAs (Fig. 4, A-F) with increased lipid vacuoles accumulation and ballooning of the hepatocytes (Fig. 5B) were observed in the livers of AG-treated rats as compared to control rats. However, normal architectures with the absence of lipid vacuoles (Fig. 5D) and normal levels of TG, CHOL, and FFAs (Fig. 4, A-E) were observed in AG + UAG-treated group. Also, lowered serum and hepatic levels of TG, CHOL, and FFAs (Fig. 4, A-E) with almost normal liver architectures
(Fig. 5C) with were reduced fat vacuoles were observed in the livers of rats administered UAG.

\section{Oxidative stress and inflammation in the livers of all groups}

Levels of GSH and ratio of GSH/GSSG were significantly decreased whereas hepatic levels of GSGG, MDA, ROS, TNF- $\alpha$, and IL- 6 were significantly increased in the livers of AG-treated rats as compared to control rats (Fig. 6, A-F). However, normal levels of all these parameters were significantly observed in UAG or AG +UAG-treated rats as compared to control rats (Fig. 6, A-F).

\section{Alterations in mRNA levels}

mRNA levels of SREBP1c, SREBP2, FAS, PPARa, and AMPKal were significantly increased in AG-treated rats as compared to control rats (Fig. 7, A\&B). On the other hand, mRNA levels of SREBP1c, SREBP2, and FAS, were significantly decreased but mRNA levels of AMPKa1 and PPARa were significantly increased in the livers of UAG-treated rats as compared to control rats (Fig 7, A\&B). However, normal levels of all these mRNAs were detected in the livers of AG + UAGtreated rats.

\section{Protein markers of hepatic insulin signaling and $E R$ stress}

Protein levels of all measured parameters were within expected weights. Total levels of IRS-1, Akt, and JNK, were not significantly changed between all groups of rats (Fig 8, A\&B, Fig 9D). Protein levels of p-Akt $\left(\mathrm{Ser}^{473}\right)$ and p-IRS1/2 $\left(\mathrm{Tyr}^{612}\right)$ and their activation ratios were significantly decreased in 


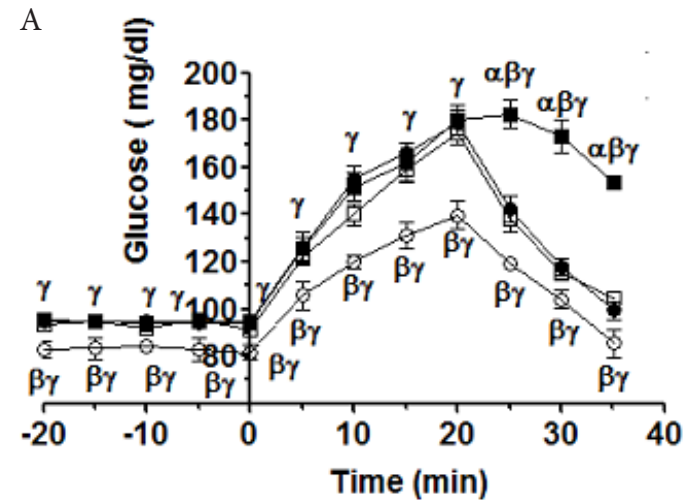

B
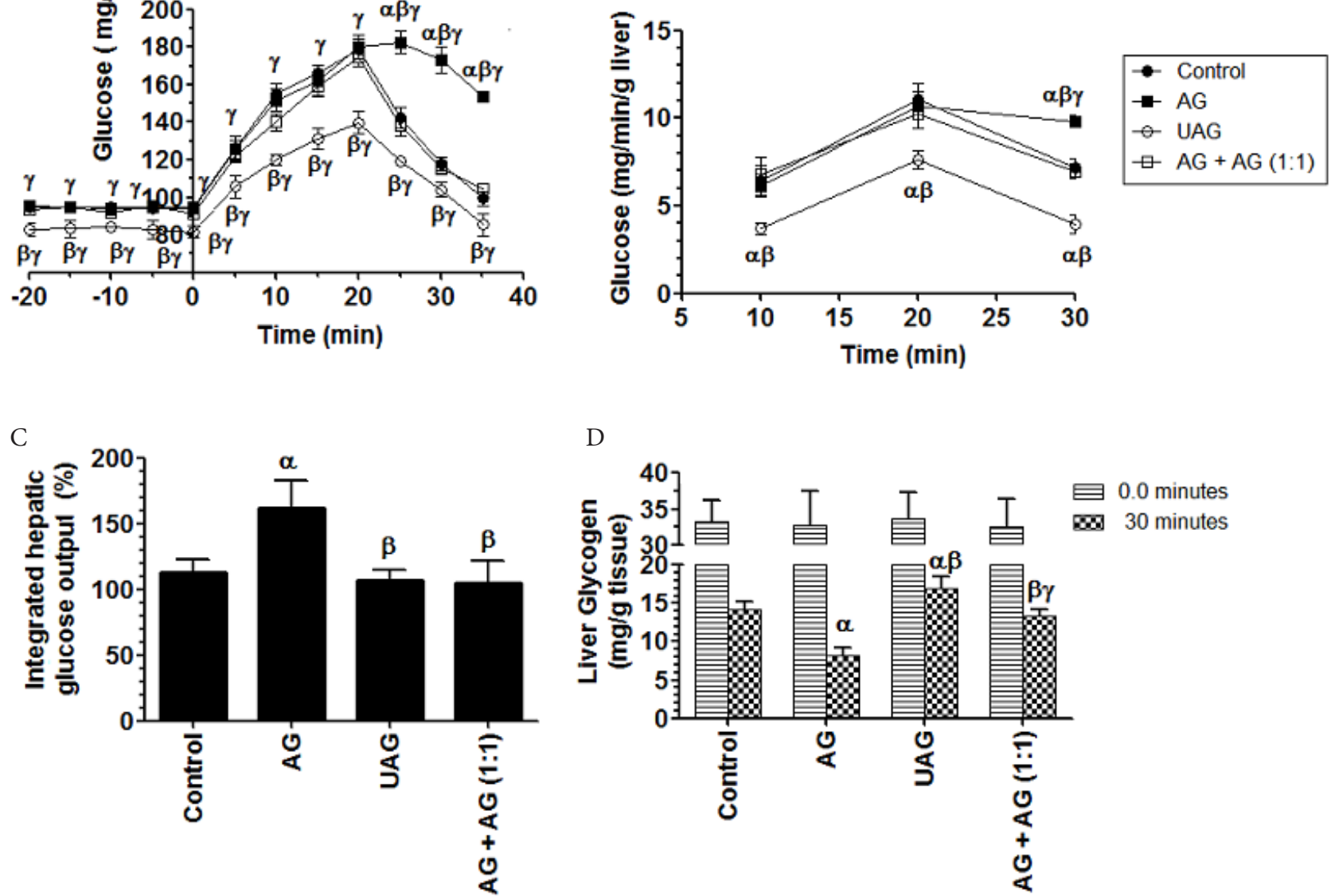

Fig. 3 Glucose production and hepatic glycogen levels in isolated liver preparations collected from all experimental groups. Data are presented as mean \pm SD in 6 rats/group. The first 20 minutes represents the period of glucose production during perfusion of glucagon alone. The last 15 minutes represents the period of glucagon + insulin perfusion. In figures A\&B; ${ }^{a}$ : vs. control rats, ${ }^{\beta}$ : vs. AG-treated rats, and v: vs. UAG-treated rats. AG: acylated ghrelin. UAG: unacylated ghrelin.
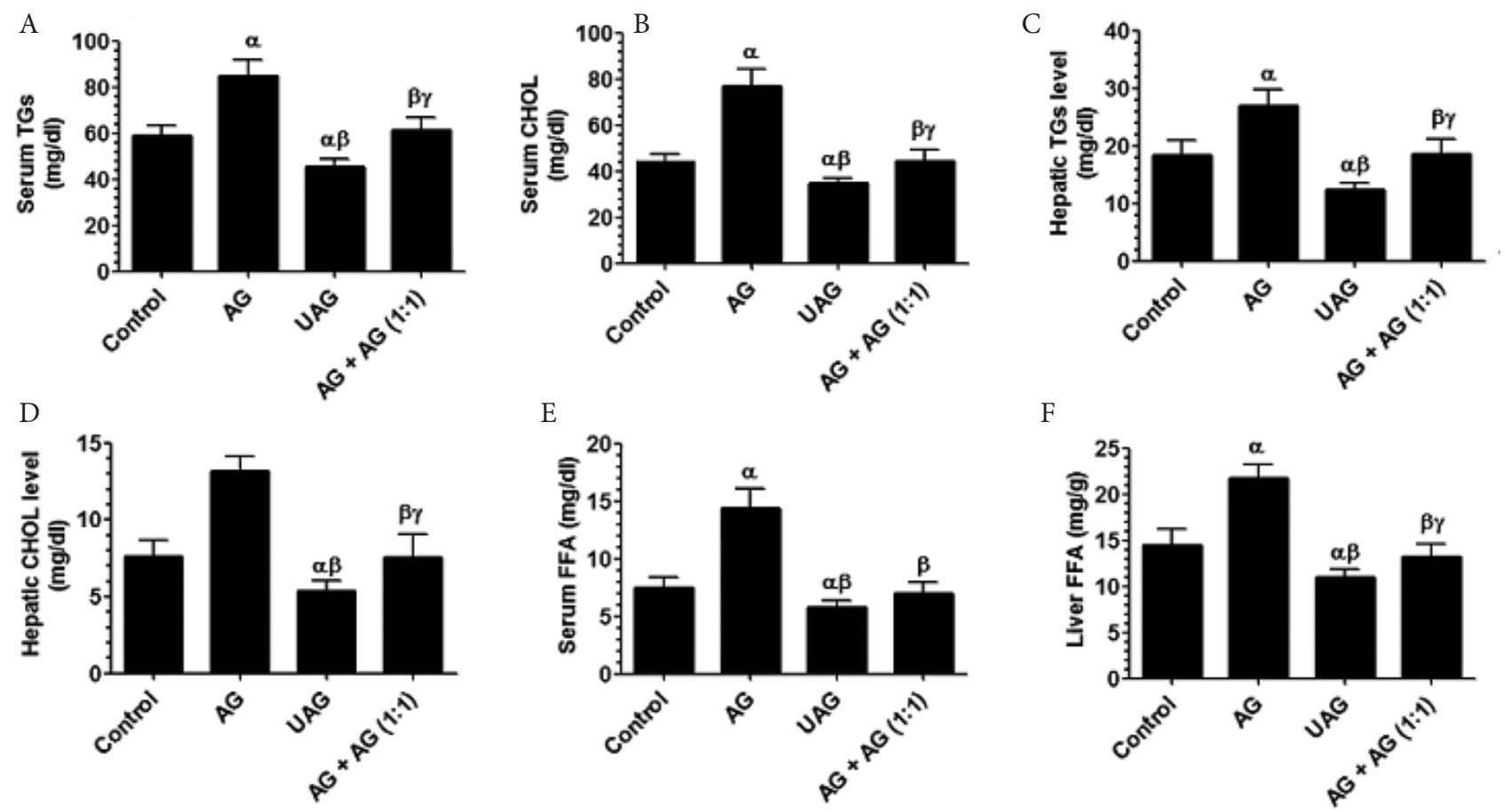

Fig. 4 Serum and hepatic levels of triglycerides (TG) (A and C), total cholesterol (CHOL) (B and D) and free fatty acids (FFAs) (E and F) in all experimental groups. Data are presented as mean \pm SD in 6 rats/group. ${ }^{a}:$ vs. control rats, ${ }^{\beta}:$ vs. AG-treated rats, and ${ }^{v}:$ vs. UAG-treated rats. AG: acylated ghrelin. UAG: unacylated ghrelin. 
AG-treated rats but significantly increased in UAG-treated rats. In addition, protein levels of p-IRS $\left(\mathrm{Ser}^{307}\right)$ and $\mathrm{p}$-JNK $\left(\mathrm{Thr}^{183}\right.$ and $\mathrm{Tyr}^{186}$ ) were significantly increased in AG-treated rats but were significantly decreased in UAG-treated rats (Fig. 8, A-D, Fig. 9D). Besides, Protein levels of PERK, p-eIF2 $\alpha$, ATF-6, CHOP, Xbp-1 were increased in AG-treated rats but significantly decreased in UAG-treated rats as compared to control rats (Fig. 9, A-D). However, protein levels of all these proteins were returned to their baseline levels in
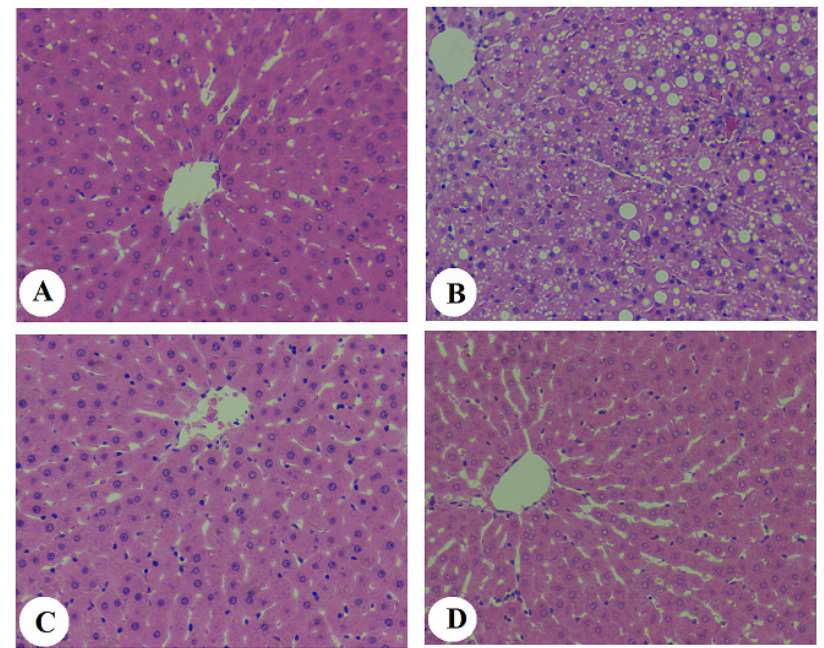

Fig. 5 Photomicrographs of liver tissues obtained from sample rats of experimental groups $A$ and $C$ : were taken from control rats and UAG-treated rats, respectively, and both showing intact polyhedral hepatocytes radiating from central vein (CV) with rounded euchromatic nuclei and intact blood sinusoids. C: was taken from AG-treated rats showing disrupted hepatocytes in which most of them filled of fat and have balooning structures. D: was taken from rat treated with AG + UAG and showing normal architectures like those observed in control rats with absence of fat vacuoles. However, some sinusoids were dilated.
$\mathrm{AG}+\mathrm{UAG}$-treated rats as compare to AG-treated rats (Fig. 9, A-D).

\section{Discussion}

In this study, we have shown that chronic administration of low dose of $\mathrm{AG}^{35}$ of not only induced fasting hyperglycaemia, hyperinsulinemia, and systemic IR, but also enhanced hepatic
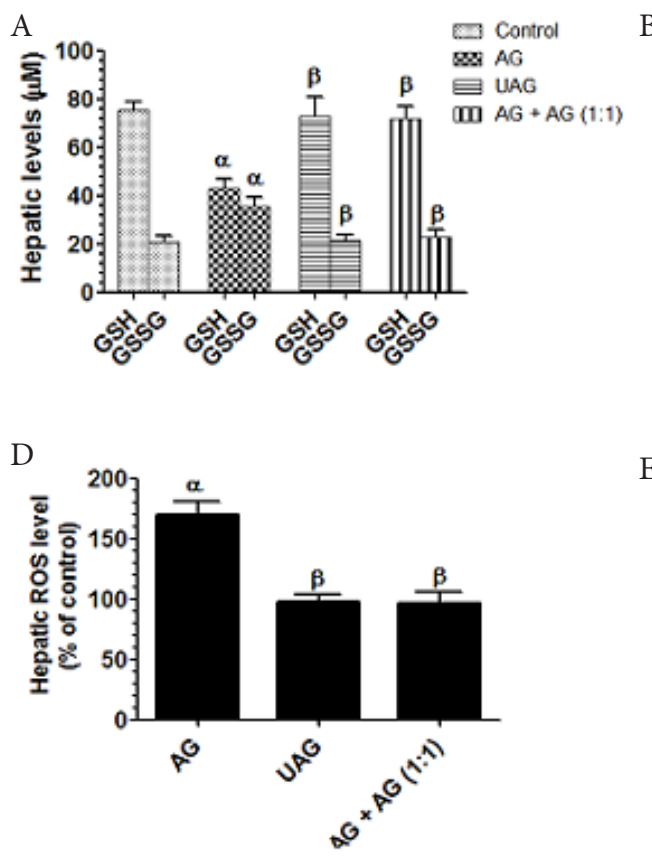
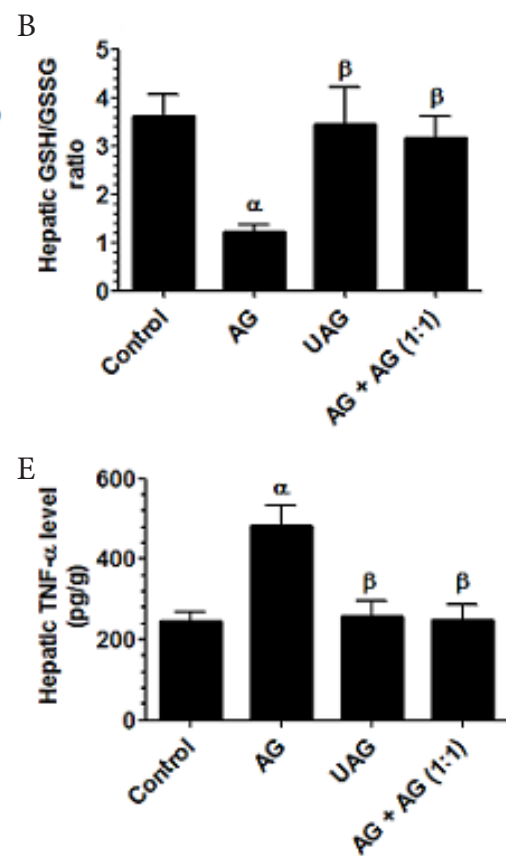
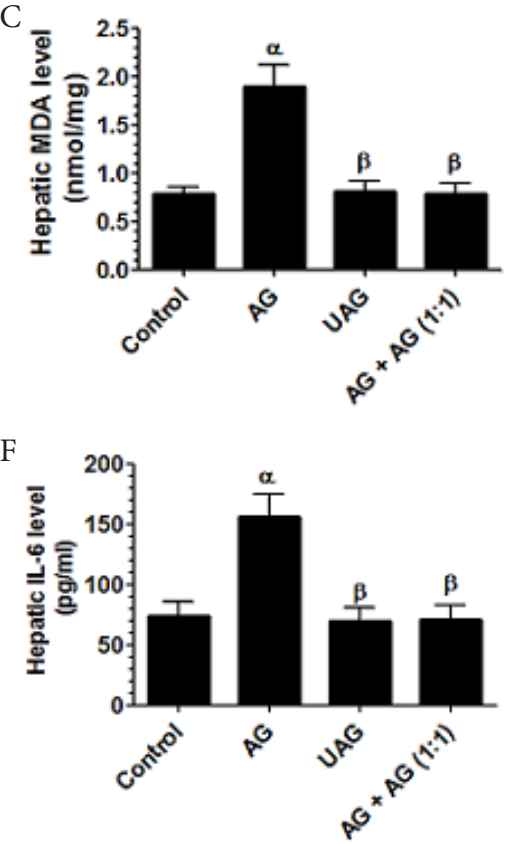

Fig. 6 Hepatic levels of markers of oxidative stress and inflammation all experimental groups. Data are presented as mean \pm SD in 6 rats/ group. ${ }^{a}:$ vs. control rats, ${ }^{\beta}$ : vs. AG-treated rats, and v?: vs. UAG-treated rats. AG: acylated ghrelin. UAG: unacylated ghrelin. 

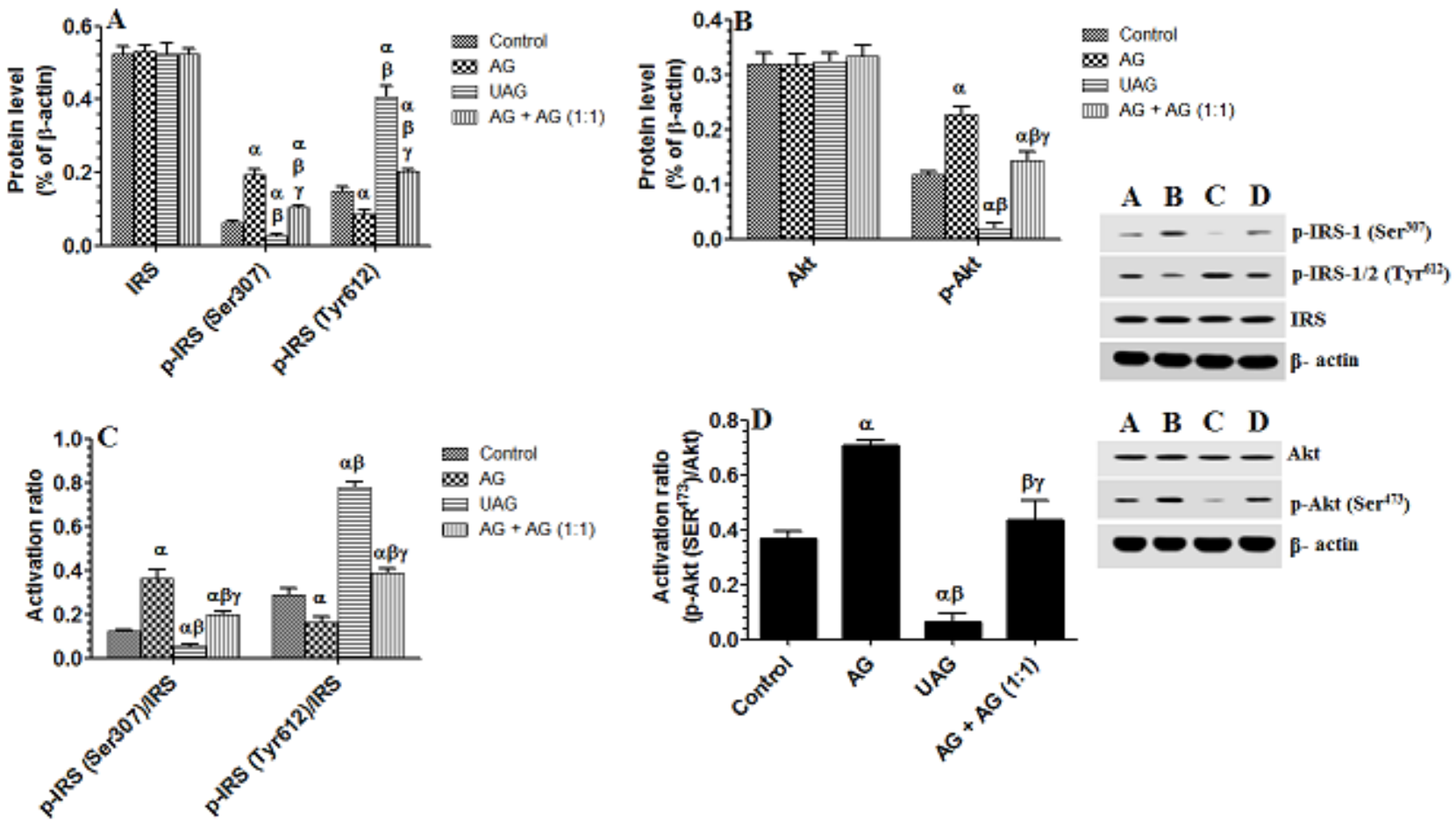

A B C D
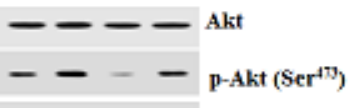

$\omega \infty$ p-actin

Fig. 8 Protein levels of markers of hepatic insulin signaling in the livers experimental groups. Data are presented as mean \pm SD in 6 rats/ group. : vs. control rats (lane A), ${ }^{\beta}$ : vs. AG-treated rats (lane B), and ${ }^{\mathrm{v}}$ : vs. UAG-treated rats (lane $\mathrm{C}$ ). lane D was taken from a rat treated with AG + UAG. AG: acylated ghrelin. UAG: unacylated ghrelin.
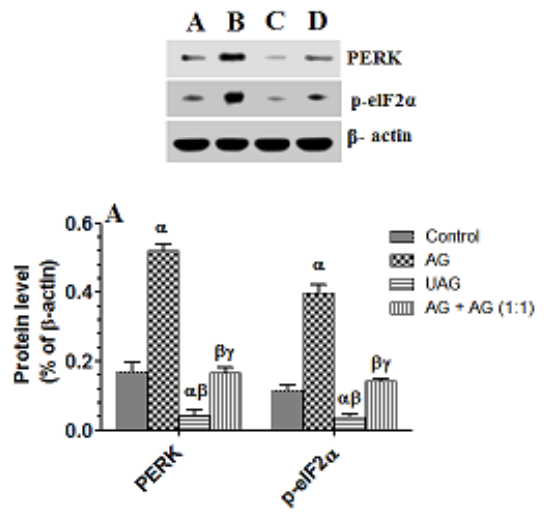

A B C D
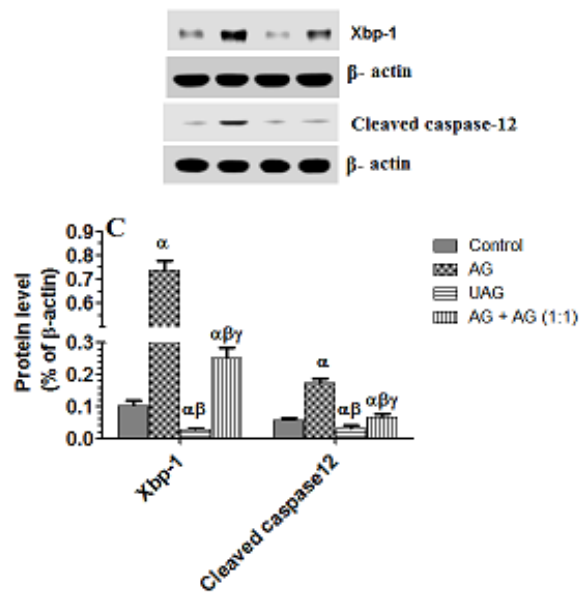

A B C D
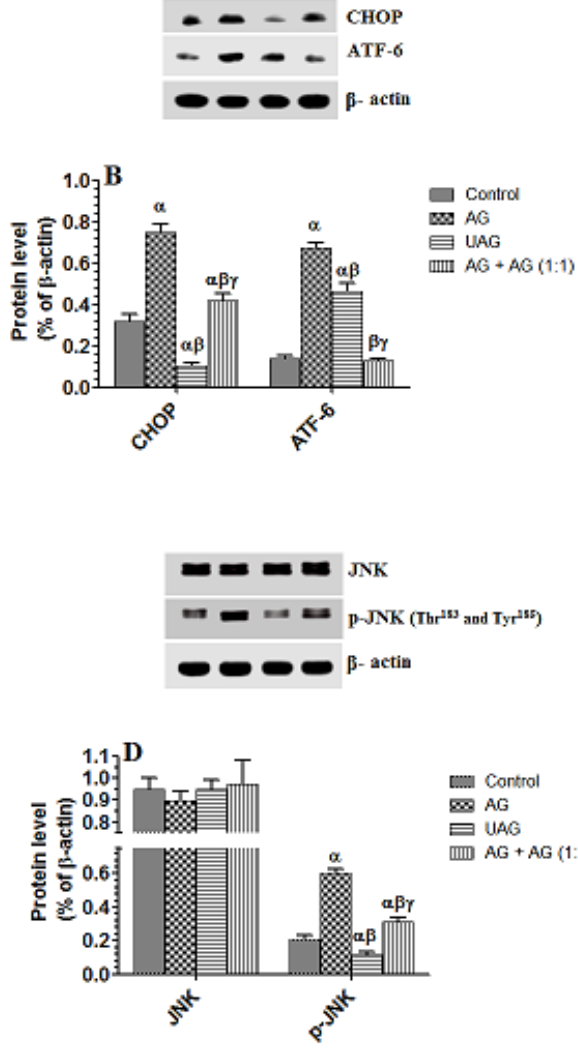

...... Control

$\$ A G$

DUG

监 $A G+A G(1: 1)$

Fig. 9 Protein levels of ER stress components in the livers experimental groups. Data are presented as mean $\pm S D$ in 6 rats/group. : $^{a}$ vs. control rats (lane A), ${ }^{\beta}$ : vs. AG-treated rats (lane B), and ${ }^{\mathrm{V}}$ : vs. UAG-treated rats (lane C). lane D was taken from a rat treated with AG + UAG. AG: acylated ghrelin. UAG: unacylated ghrelin. 
lipogenesis and suppressed hepatic insulin signaling associated with upregulation of SREBP1/2 and FAS expression, oxidative stress, inflammation, and activation of UPR and ER stress. On the contrary, chronic administration of UAG afforded opposite effects with no effect of fasting insulin levels but concomitant with activation of ATF- 6 arm of UPR and upregulation of AMPK and PPARa, major inducers of mitochondria FAs oxidation. Besides, co-administration of UAG with $\mathrm{AG}$, in a ratio of $1: 1$, attenuated systemic and hepatic effects exerted by AG and suppressed hepatic lipogenesis, IR, oxidative stress, inflammation, and ER stress.

The first interesting observation in this study is that all the biochemical and molecular alterations observed in AG and UAG-treated rats of this study seem to be independent of food intake and orexigenic role of ghrelin as all experimental groups of rats consumed a similar amount of diet during the whole period of the study. Supporting these findings, the s.c. individual or combination of both AG and UAG at the same doses and 14 days used in this study didn't modify food intake in rats. ${ }^{27}$ Also, a very weak increase in food intake was shown after AG injection and neither the s.c nor the centrally infused AG increased food consumption..$^{40-42}$ On the other hand, AG-treated rats developed peripheral and hepatic IR. Peripheral IR was evident by the observed fasting hyperglycaemia and hyperinsulinemia, lower hepatic and muscle glycogen contents, a higher value of HOMA-IRI, and the increase in plasma glucose and insulin levels at all measured intervals after the OGTT. However, we also confirmed the hepatic IR in AG-treated rats by the increase in glucose production during the infusion of combined glucagon and insulin in the isolated liver preparation that indicates the inability of insulin to suppress glucagon-induced gluconeogenesis. To confirm these results, we have also studied the activity of insulin signaling in the livers of AG-treated rats and found that AG increased the IRS $\left(\mathrm{Ser}^{307}\right)$ and $\mathrm{p}$-JNK $\left(\mathrm{Thr}^{183}\right.$ and $\left.\mathrm{Tyr}^{185}\right)$ and decrease protein levels of IRS ( $\left.\mathrm{Tyr}^{612}\right)$ and p-Akt $\left(\operatorname{Ser}^{473}\right)$.

Similar to these data, short and long-term administration of AG, and independent of food intake or growth hormones, increased hepatic gluconeogenesis, increased glucose output, and/or impaired hepatic and peripheral insulin sensitivity. ${ }^{27,32,43,44}$ However, some other studies have shown that AG administration could not affect, ${ }^{45}$ increases insulin levels, ${ }^{46}$ or improves peripheral insulin sensitivity. ${ }^{27,47}$ Such variation in our data and those studies could be attributed to inter-experimental conditions which could reflect different doses, treatment period, administration way (systemic vs. central), and/or species used.

On the contrary, the opposite effects of fasting hypoglycaemia but with no alterations in fasting insulin levels were seen in UAG-treated rats. Besides, co-administration of UAG with AG at a ratio of 1:1 reversed AG-induced alteration in all the above-mentioned biochemical parameters and stimulated hepatic insulin signaling. These data suggest that UAG can reduce fasting hyperglycemia and improves peripheral and hepatic insulin sensitivity which is also supported by other previous studies. $27,31,48,49$

What is considered unique is that we have also found that livers obtained from UAG have reduced glucose production upon infusion of glucagon alone, thus illustrating UAG as an inhibitor of gluconeogenesis. This could be attributed to the improvement in hepatic insulin sensitivity. Interestingly, we also found a slight but significant increase in ATF-6 protein levels (a transmembrane protein that is released in ER stress) in the liver of these rats (as discussed later). Glucagon stimulates hepatic gluconeogenesis through the CREB regulated transcription coactivator 2 (CRTC2).$^{50}$ ATF6 transient activation was shown to inhibit hepatic glucose output by inhibiting CRTC2 occupancy at the promoters of genes that are involved in gluconeogenesis. ${ }^{50}$ This is could be a novel mechanism by which UAG inhibits glucose production in the hepatocytes.

Under IR, the adipose tissue and muscular lipolysis are increased. As a result, the influx of the FFAs to the liver increases and stimulated the generation of ROS and inflammatory cytokines, lipid peroxidation, and hepatocytes damage due to increased $\beta$-oxidation and mitochondria dysfunction and leads to the generation of ROS, lipid peroxidation, depletion of antioxidants, inflammation, which in turn damage the hepatocytes. ${ }^{51}$ FFAs can directly induce ER stress in the liver cells by stimulating store-operated $\mathrm{Ca}^{2+}$ entry and activation of calpain-2. ${ }^{52}$ Nonetheless, ROS and inflammatory cytokines activate hepatic ER stress. ${ }^{53}$ Moreover, ER stress is known to induce hepatic IR through IRE1 $\alpha$-mediated activation of c-Jun $\mathrm{N}$-terminal kinase (JNK), which in turn, impairs insulin signalling through increasing Ser ${ }^{307}$ phosphorylation of IRS-1. ${ }^{54-57}$ Also, oxidative stress can suppress hepatic insulin signaling in different tissues by activating stress pathways involving a family of serine/threonine kinases and oxidation of the mediator proteins..$^{58}$

In the same line with these studies, we have also found an increase in the serum and hepatic levels of FFAs with a concomitant increase in hepatic ROS, TNF- $\alpha$, and IL-6 and a reduction in hepatic and muscles glycogen, thus suggesting that AG pro-oxidant effect is mediated by stimulating peripheral lipolysis. This possibly due to stimulating muscle lipolysis but not that of adipose tissue as suggested by other authors. ${ }^{32,59,60}$ Similar to our data, the infusion of AG increased plasma levels of NEFA plasma non-esterified FAs (NEFAs). ${ }^{42,61}$ Besides, AG-increased the expression of IRE1a and induced activation of JNK and phosphorylation of IRS $\left(\mathrm{Ser}^{307}\right)$ which were reduced in the livers of UAG-treated rats and attenuated in the livers of AG-treated rats which co-administered UAG. Also, individual or combined administration of UAG with AG reduced the levels of FFAs and suppressed the hepatic oxidative stress and inflammatory response. Since the liver lacks AG receptors (GSHR-1a), ${ }^{62}$ these data suggest that the hepatic effect of both AG and UG on markers of oxidative stress, inflammation, and insulin signaling are controlled by modulating peripheral insulin sensitivity, FFAs influx and possibly through the unidentified peripheral or hepatic receptor. This requires further studies.

On the other hand, previous studies have shown that AG-stimulates hepatic FAs synthesis related genes and suppresses FAs oxidation whereas UAG suppresses hepatic lipid accumulation by increasing FAs oxidation. ${ }^{25,27,30,32,36}$ AMPKa1 is a negative inhibitor of SREBPs and potent inducer of PPAR $a$ and other $\beta$-oxidation genes (Dallak, 2018b). On the other hand, insulin is a potent inducer of SREBP $1 / 2$ in the mammalian liver. ${ }^{51,53}$ Similar to these studies, we have also found that AG-stimulated hepatic lipogenesis and fat accumulation are associated with increasing the mRNA levels of SREBP1/2 and FAS. On the other hand, individual administration of UAG to healthy rats or in combination with AG reduced the hepatic mRNA levels of these lipogenic enzymes. However, both AG and UAG increased the mRNA of AMPK and PPARa. 
Therefore, it seems reasonable that the anti-lipogenic effect of UAG is mediated by suppressing FAs synthesis genes and stimulating FAs oxidation by upregulating/activating AMPK/ PPAR $a$ axis. However, it seems logical that the activation of AMPK/PPARa by AG treatment is a compensatory mechanism to reduce fatty acid synthesis and fat accumulation or due to increased FFAs influx. Indeed, FFAs can activate AMPK and PPARa in the different tissues including the livers and cardiomyocytes. ${ }^{58,63,64}$ Also, and given the higher fasting insulin levels, it could be possible that AG increases the activation of SREBP $1 / 2$ and FAS by the resulted hyperinsulinemia. However, since FFAs were significantly decreased and insulin levels were not significantly altering in UAG-treated rats, we could suggest that UAG suppresses lipogenic genes and stimulates AMPK by a direct effect on the liver and possibly by reducing oxidative stress and inflammation.

Although this provides some possible explanation for the effect of AG and UAG on hepatic lipid metabolism, the precise mechanisms by which both ghrelin forms regulate this is largely unknown. On interesting area is the emerging role of ER stress in hepatic lipid metabolism. ${ }^{65}$ Within most cells including the hepatocytes, accumulation of unfolded proteins in the ER due to the increase in metabolic activity, triggers unfolded protein response (UPR) via activation of three transmembrane signal transducers, namely inositol-requiring enzyme-1 (IRE-1), activating transcription factor-6 (ATF-6), and protein kinase RNA-like ER kinase (PERK), mediated by dissociation of chaperone immunoglobulin heavy-chainbinding protein (BiP; also known as GRP78. ${ }^{5}$ These events are associated with phosphorylation and inhibition eukaryotic translation initiation factor $2 \alpha$ (eiF $2 \alpha$ ), activation of transcription factor 4 (ATF4), splicing of X-box-binding protein-1 (XBP1), all of which aid to inhibit protein synthesis to enhance cell survival. ${ }^{65}$ As mentioned before, higher levels of FFAs, ROS, and inflammatory cytokines can also activate hepatic UPR and ER stress. ${ }^{52,53}$

Nonetheless, unresolved UPR and ER stress activates numerous arms that induce hepatic steatosis. ${ }^{65,}{ }^{66}$ Indeed, the activation of the PERK/eIF2 $\alpha$-/ATF4 pathway induces hepatic steatosis by upregulating SREBPs, FAS, and stearoyl-CoA desaturase-1 (SCD1).8, 50, 67, 68 Also, phosphorylation of eIF2a induces glucose intolerance and exaggerates hepatic lipid synthesis and steatosis in rodent. ${ }^{8}$ In the same line, upregulation of CHOP, a downstream target of p-eIF2 $\alpha$, increases hepatic gluconeogenesis and lipid deposition and stimulates hepatocytes apoptosis. ${ }^{66,69}$ Besides, IRE1a/Xbp-1pathway induced hepatic lipogenesis by the binding of $\mathrm{Xbp}-1$ to the promoters of SCD1, diacylglycerol acyltransferase-2 (DGAT2), and ACC-1, thus inducing their activation. ${ }^{9}$ This could explain the findings of Dallak ${ }^{27}$ who failed to explain why the livers of AG-treated rats have increased expression of DGAT-2 which was reduced with the treatment with UAG.

In this study, chronic administration of AG activated UPR and ER stress in the liver of rats as shown by the significant increase in hepatic levels of PERK, ATF6, IRE1a, and their downstream targets p-eIF2 $\alpha$, ATF4, CHOP, and Xbp-1. This could be due to increased hepatic levels of FFAs, ROS, and inflammatory cytokines due to the peripheral IR as described above. On the contrary, chronic administration of UAG- significantly inhibited the expression of all these biochemical markers, except for ATF-6 which showed a slight but significant increase. Besides, co-administration of UAG with AG reversed all its effects on these markers. Based on these data, we concluded that that AG induces hepatic steatosis and IR by inducing ER stress where UAG prevents these events by suppressing ER and activating ATF6 possibly due to improving insulin sensitivity. Interestingly, ATF6 causes an increase in AMPK expression and FAs oxidation to rescue cells from lipotoxicity. ${ }^{70}$ This could help us to explain the increased FAs oxidation in the livers of UAG-treated rats.

In conclusion, our data suggest that AG induces hepatic steatosis and IR by increasing oxidative stress, inflammation, and ER stress, at least through inducing peripheral IR. However, UAG protective effect is mediated by contradictory mechanisms. Also, our data suggest that a balanced ratio of AG/UAG is crucial to preserve normal glucose, insulin, and lipid metabolism.

Although our data suggest that the lipogenic effect of AG and anti-lipogenic effects of UAG mediated by modulating the peripheral IR, other mechanisms including unidentified hepatic or systemic receptor and modulating growth hormones and parasympathetic flow were not investigated in this study. Indeed, several authors have suggested that the hepatic effect of AG is mediated indirectly by altering the levels of growth hormones, the vagus nerve, and unidentified hepatic receptors. ${ }^{28,71-73}$ Besides, our data remain descriptive and if the effects of AG and UAG ER stress are mediated by a direct effect or through peripheral insulin-dependent mechanism can't be definitely judged form these data. Therefore, further studies in genetically modified animals and isolated hepatocytes lacking some arms of ER are needed to validate our data. Besides, further studies using an ER inhibitors may help to better understanding these results.

\section{Acknowledgment}

The authors would like to express their gratitude to the College of Medicine at King Khalid University for their help in conducting the animal part of this study. They also would like to thank the technical staff for their help in measurements of some parameters under the supervision of Dr. Refaat Eid for his significant contribution to this study at the Department of Biology. The authors can extend their thanks to the Deanship of Scientific Research at Umm Al-Qura University for supporting this project by Grant Code: 10-MED-1-03-0004.

\section{Conflicts of Interest}

The authors declare no conflicts of interest.

\footnotetext{
References

1. Malaguarnera, M., Di Rosa, M., Nicoletti, F. \& Malaguarnera, L. 2009. Molecular mechanisms involved in NAFLD progression. Journal of molecular medicine, 87, 679.

2. Cohen, J. C., Horton, J. D. \& Hobbs, H. H. 2011. Human fatty liver disease: old questions and new insights. Science, 332, 1519-1523.
}

3. Zhang, S. R. \& Fan, X. M. 2015. Ghrelin-ghrelin O-acyltransferase system in the pathogenesis of nonalcoholic fatty liver disease. World Journal of Gastroenterology: WJG, 21, 3214.

4. Te Sligte, K., Bourass, I., Sels, J., Driessen, A., Stockbrügger, R. \& Koek, G. 2004. Non-alcoholic steatohepatitis: review of a growing medical problem. European journal of internal medicine, 15, 10 -21. 
5. Zhang, X. Q., Xu, C. F., Yu, C. H., Chen, W. X. \& Li, Y.-M. 2014a. Role of endoplasmic reticulum stress in the pathogenesis of nonalcoholic fatty liver disease. World journal of gastroenterology: WJG, 20, 1768

6. Tabas, I. \& Ron, D. 2011. Integrating the mechanisms of apoptosis induced by endoplasmic reticulum stress. Nature cell biology, 13, $184-190$.

7. Özcan, U., Cao, Q., Yilmaz, E., Lee, A.-H., Iwakoshi, N. N., Özdelen, E., Tuncman, G., Görgün, C., Glimcher, L. H. \& Hotamisligil, G. S. 2004. Endoplasmic reticulum stress links obesity, insulin action, and type 2 diabetes. Science, $306,457-461$.

8. Oyadomari, S., Harding, H. P., Zhang, Y., Oyadomari, M. \& Ron, D. 2008. Dephosphorylation of translation initiation factor $2 a$ enhances glucose tolerance and attenuates hepatosteatosis in mice. Cell metabolism, 7, 520 $-532$.

9. Lee, A. H., Scapa, E. F., Cohen, D. E. \& Glimcher, L. H. 2008. Regulation of hepatic lipogenesis by the transcription factor XBP1. Science, 320, 1492 -6.

10. Ji, C. 2014. New insights into the pathogenesis of alcohol-induced ER stress and liver diseases. International journal of hepatology, 2014.

11. Chan, S.-W. 2014. Unfolded protein response in hepatitis C virus infection. Frontiers in microbiology, 5, 233.

12. Wang, D., Wei, Y. \& Pagliassotti, M. J. 2006. Saturated fatty acids promote endoplasmic reticulum stress and liver injury in rats with hepatic steatosis. Endocrinology, 147, 943 -951.

13. Rahman, S. M., Schroeder-Gloeckler, J. M., Janssen, R. C., Jiang, H., Qadri, I., Maclean, K. N. \& Friedman, J. E. 2007. CCAAT/enhancing binding protein $\beta$ deletion in mice attenuates inflammation, endoplasmic reticulum stress, and lipid accumulation in diet-induced nonalcoholic steatohepatitis. Hepatology, 45, $1108-1117$

14. Puri, P., Mirshahi, F., Cheung, O., Natarajan, R., Maher, J. W., Kellum, J. M. \& Sanyal, A. J. 2008. Activation and dysregulation of the unfolded protein response in nonalcoholic fatty liver disease. Gastroenterology, 134, 568 -576.

15. Gregor, M. F., Yang, L., Fabbrini, E., Mohammed, B. S., Eagon, J. C., Hotamisligil, G. S. \& Klein, S. 2009. Endoplasmic reticulum stress is reduced in tissues of obese subjects after weight loss. Diabetes, 58, $693-700$.

16. Rinella, M. E., Siddiqui, M. S., Gardikiotes, K., Gottstein, J., Elias, M. \& Green, R. M. 2011. Dysregulation of the unfolded protein response in $\mathrm{db} / \mathrm{db}$ mice with diet-induced steatohepatitis. Hepatology, 54, 1600 -1609.

17. Fang, D.-L., Wan, Y., Shen, W., Cao, J., Sun, Z.-X., Yu, H.-H., Zhang, Q., Cheng, W.-H., Chen, J. \& Ning, B. 2013. Endoplasmic reticulum stress leads to lipid accumulation through upregulation of SREBP-1c in normal hepatic and hepatoma cells. Molecular and cellular biochemistry, 381, $127-137$.

18. Ozawa, K., Miyazaki, M., Matsuhisa, M., Takano, K., Nakatani, Y., Hatazaki, M., Tamatani, T., Yamagata, K., Miyagawa, J.-I. \& Kitao, Y. 2005. The endoplasmic reticulum chaperone improves insulin resistance in type 2 diabetes. Diabetes, 54, $657-663$.

19. Nakatani, Y., Kaneto, H., Kawamori, D., Yoshiuchi, K., Hatazaki, M., Matsuoka, T.-A., Ozawa, K., Ogawa, S., Hori, M. \& Yamasaki, Y. 2005. Involvement of endoplasmic reticulum stress in insulin resistance and diabetes. Journal of Biological Chemistry, 280, $847-851$.

20. Kammoun, H. L., Chabanon, H., Hainault, I., Luquet, S., Magnan, C., Koike, T., Ferré, P. \& Foufelle, F. 2009. GRP78 expression inhibits insulin and ER stress - induced SREBP-1c activation and reduces hepatic steatosis in mice. The Journal of clinical investigation, 119, $1201-1215$.

21. Gualillo, O., Lago, F. \& Dieguez, C. 2008. Introducing GOAT: a target for obesity and anti-diabetic drugs? Trends in pharmacological sciences, 29, $398-401$.

22. Soares, J.-B., Roncon-Albuquerque Jr, R. \& Leite-Moreira, A. 2008. Ghrelin and ghrelin receptor inhibitors: agents in the treatment of obesity. Expert opinion on therapeutic targets, 12, $1177-1189$

23. Estep, M., Abawi, M., Jarrar, M., Wang, L., Stepanova, M., Elariny, H., Moazez, A., Goodman, Z., Chandhoke, V. \& Baranova, A. 2011. Association of obestatin, ghrelin, and inflammatory cytokines in obese patients with nonalcoholic fatty liver disease. Obesity surgery, 21, 1750 -1757.

24. Li, Y., Hai, J., Li, L., Chen, X., Peng, H., Cao, M. \& Zhang, Q. 2013. Administration of ghrelin improves inflammation, oxidative stress, and apoptosis during and after non-alcoholic fatty liver disease development. Endocrine, 43, $376-386$

25. Li, Z., Xu, G., Qin, Y., Zhang, C., Tang, H., Yin, Y., Xiang, X., Li, Y., Zhao, J. \& Mulholland, M. 2014. Ghrelin promotes hepatic lipogenesis by activation of mTOR-PPARy signaling pathway. Proceedings of the National Academy of Sciences, 111, $13163-13168$

26. Arslan, N., Sayin, O. \& Tokgoz, Y. 2014. Evaluation of serum xenin and ghrelin levels and their relationship with nonalcoholic fatty liver disease and insulin resistance in obese adolescents. Journal of endocrinological investigation, 37, $1091-1097$.
27. Dallak, M. A. 2018b. Acylated ghrelin induces but deacylated ghrelin prevents hepatic steatosis and insulin resistance in lean rats: effects on DAG/PKC/JNK pathway. Biomedicine \& Pharmacotherapy, 105, 299-311.

28. Zhang, Y., Fang, F., Goldstein, J. L., Brown, M. S. \& Zhao, T.-J. 2015. Reduced autophagy in livers of fasted, fat-depleted, ghrelin-deficient mice: reversal by growth hormone. Proceedings of the National Academy of Sciences, 112, $1226-1231$.

29. Lim, C. T., Kola, B., Grossman, A. \& Korbonits, M. 2011. The expression of ghrelin 0-acyltransferase (GOAT) in human tissues. Endocrine journal, 58, $707-710$.

30. Kola, B., Hubina, E., Tucci, S. A., Kirkham, T. C., Garcia, E. A., Mitchell, S. E., Williams, L. M., Hawley, S. A., Hardie, D. G. \& Grossman, A. B. 2005. Cannabinoids and ghrelin have both central and peripheral metabolic and cardiac effects via AMP-activated protein kinase. Journal of Biological Chemistry, 280, $25196-25201$.

31. Barazzoni, R., Zanetti, M., Ferreira, C., Vinci, P., Pirulli, A., Mucci, M., Dore, F., Fonda, M., Ciocchi, B. \& Cattin, L. 2007. Relationships between desacylated and acylated ghrelin and insulin sensitivity in the metabolic syndrome. The Journal of Clinical Endocrinology \& Metabolism, 92, 3935 -3940.

32. Barazzoni, R., Bosutti, A., Stebel, M., Cattin, M. R., Roder, E., Visintin, L., Cattin, L., Biolo, G., Zanetti, M. \& Guarnieri, G. 2005. Ghrelin regulates mitochondrial-lipid metabolism gene expression and tissue fat distribution in liver and skeletal muscle. American Journal of Physiology-Endocrinology and Metabolism

33. Rigault, C., Le Borgne, F., Georges, B. \& Demarquoy, J. 2007. Ghrelin reduces hepatic mitochondrial fatty acid $\beta$ oxidation. Journal of endocrinological investigation, 30, RC4-RC8.

34. Porteiro, B., Díaz-Ruíz, A., Martínez, G., Senra, A., Vidal, A., Serrano, M., Gualillo, O., López, M., Malagón, M. M. \& Diéquez, C. J. E. 2013. Ghrelin requires p53 to stimulate lipid storage in fat and liver. 154, 3671 -3679.

35. Dallak, M. A. 2018a. Acylated ghrelin induces but deacylated ghrelin prevents hepatic steatosis and insulin resistance in lean rats: Effects on DAG/PKC/JNK pathway. 105, 299 -311.

36. Delhanty, P. J., Sun, Y., Visser, J. A., Van Kerkwijk, A., Huisman, M., Van ljcken, W. F., Swagemakers, S., Smith, R. G., Themmen, A. P. \& Van Der Lely, A.-J. 2010. Unacylated ghrelin rapidly modulates lipogenic and insulin signaling pathway gene expression in metabolically active tissues of GHSR deleted mice. PloS one, 5, e11749.

37. Ezquerro, S., Méndez-Giménez, L., Becerril, S., Moncada, R., Valentí, V., Catalán, V., Gómez-Ambrosi, J., Frühbeck, G. \& Rodríguez, A. 2016. Acylated and desacyl ghrelin are associated with hepatic lipogenesis, $\beta$-oxidation and autophagy: role in NAFLD amelioration after sleeve gastrectomy in obese rats. Scientific reports, 6, $1-12$.

38. Khaleel, E. F., Abdel-Aleem, G. A. \& Mostafa, D. G. 2018. Resveratrol improves high-fat diet induced fatty liver and insulin resistance by concomitantly inhibiting proteolytic cleavage of sterol regulatory element-binding proteins, free fatty acid oxidation, and intestinal triglyceride absorption. Canadian journal of physiology and pharmacology, 96, 145-157.

39. Roden, M., Prskavec, M., Fürnsinn, C., Elmadfa, I., König, J., Schneider, B., Wagner, O. \& Waldhäusl, W. 1995. Metabolic effect of sodium selenite: Insulin-like inhibition of glucagon-stimulated glycogenolysis in the isolated perfused rat liver. Hepatology, 22, 169-174.

40. Wertz-Lutz, A., Knight, T., Pritchard, R., Daniel, J., Clapper, J., Smart, A., Trenkle, A. \& Beitz, D. 2006. Circulating ghrelin concentrations fluctuate relative to nutritional status and influence feeding behavior in cattle. Journal of Animal Science, 84, $3285-3300$.

41. Iqbal, J., Kurose, Y., Canny, B. \& Clarke, I. J. 2006. Effects of central infusion of ghrelin on food intake and plasma levels of growth hormone, luteinizing hormone, prolactin, and cortisol secretion in sheep. Endocrinology, 147, 510 $-519$.

42. Roche, J., Sheahan, A., Chagas, L., Blache, D., Berry, D. \& Kay, J. 2008. Longterm infusions of ghrelin and obestatin in early lactation dairy cows. Journal of Dairy Science, 91, $4728-4740$.

43. Murata, M., Okimura, Y., lida, K., Matsumoto, M., Sowa, H., Kaji, H., Kojima, M., Kangawa, K. \& Chihara, K. 2002. Ghrelin modulates the downstream molecules of insulin signaling in hepatoma cells. Journal of Biological Chemistry, 277, $5667-5674$.

44. Gauna, C., Meyler, F., Janssen, J., Delhanty, P., Abribat, T., Van Koetsveld, P., Hofland, L., Broglio, F., Ghigo, E. \& Van Der Lely, A. J. 2004. Administration of acylated ghrelin reduces insulin sensitivity, whereas the combination of acylated plus unacylated ghrelin strongly improves insulin sensitivity. The Journal of Clinical Endocrinology \& Metabolism, 89, 5035 -5042.

45. Kamegai, J., Tamura, H., Shimizu, T., Ishii, S., Sugihara, H. \& Wakabayashi, I. 2001. Chronic central infusion of ghrelin increases hypothalamic 
neuropeptide $Y$ and Agouti-related protein mRNA levels and body weight in rats. Diabetes, 50, $2438-2443$.

46. Stevanović, D., Nešić, D., Milošević, V., Starčević, V. \& Severs, W. B. 2008. Consummatory behavior and metabolic indicators after central ghrelin injections in rats. Regulatory peptides, 147, 52 -59.

47. Theander-Carrillo, C., Wiedmer, P., Cettour-Rose, P., Nogueiras, R., Perez-Tilve, D., Pfluger, P., Castaneda, T. R., Muzzin, P., Schürmann, A. \& Szanto, I. 2006. Ghrelin action in the brain controls adipocyte metabolism. The Journal of clinical investigation, 116, $1983-1993$.

48. Zhang, W., Chai, B., Li, J. Y., Wang, H. \& Mulholland, M. W. 2008. Effect of des-acyl ghrelin on adiposity and glucose metabolism. Endocrinology, 149, $4710-4716$.

49. Cederberg, H., Koivisto, V. M., Jokelainen, J., Surcel, H. M., KeinänenKiukaanniemi, S. \& Rajala, U. 2012. Unacylated ghrelin is associated with changes in insulin sensitivity and lipid profile during an exercise intervention. Clinical endocrinology, 76, 39-45.

50. Wang, C., Huang, Z., Du, Y., Cheng, Y., Chen, S. \& Guo, F. 2010. ATF4 regulates lipid metabolism and thermogenesis. Cell research, 20, $174-184$.

51. Utzschneider, K. M. \& Kahn, S. E. 2006. The role of insulin resistance in nonalcoholic fatty liver disease. The Journal of Clinical Endocrinology \& Metabolism, 91, $4753-4761$.

52. Cui, W., Ma, J., Wang, X., Yang, W., Zhang, J. \& Ji, Q. 2013. Free fatty acid induces endoplasmic reticulum stress and apoptosis of $\beta$-cells by $\mathrm{Ca} 2+1$ calpain-2 pathways. PloS one, 8, e59921.

53. Kawasaki, N., Asada, R., Saito, A., Kanemoto, S. \& Imaizumi, K. 2012. Obesityinduced endoplasmic reticulum stress causes chronic inflammation in adipose tissue. Scientific reports, 2, 799

54. Du, K., Herzig, S., Kulkarni, R. N. \& Montminy, M. 2003. TRB3: a tribbles homolog that inhibits Akt/PKB activation by insulin in liver. Science, 300, $1574-1577$.

55. Zhang, X. Q., Xu, C. F., Yu, C. H., Chen, W. X. \& Li, Y. M. 2014c. Role of endoplasmic reticulum stress in the pathogenesis of nonalcoholic fatty liver disease. World J Gastroenterol, 20, 1768-76.

56. Nakae, J., Biggs, W. H., Kitamura, T., Cavenee, W. K., Wright, C. V., Arden, K. C. \& Accili, D. 2002. Regulation of insulin action and pancreatic $\beta$-cell function by mutated alleles of the gene encoding forkhead transcription factor Foxo1. Nature genetics, 32, $245-253$.

57. Kim, J. J., Li, P., Huntley, J., Chang, J. P., Arden, K. C. \& Olefsky, J. M. 2009 FoxO1 haploinsufficiency protects against high-fat diet -induced insulin resistance with enhanced peroxisome proliferator-activated receptor $\gamma$ activation in adipose tissue. Diabetes, 58, 1275 -1282.

58. Rains, J. L. \& Jain, S. K. 2011. Oxidative stress, insulin signaling, and diabetes. Free Radical Biology and Medicine, 50, $567-575$.

59. Grala, T., Kay, J., Walker, C., Sheahan, A., Littlejohn, M., Lucy, M. \& Roche, J. 2010. Expression analysis of key somatotropic axis and liporegulatory genes in ghrelin-and obestatin-infused dairy cows. Domestic animal endocrinology, 39, 76-83.
60. Vestergaard, E. T., Buhl, M., Gjedsted, J., Madsen, M., Jessen, N., Nielsen, S., Gaylinn, B. D., Liu, J., Thorner, M. O. \& Moller, N. 2011. Acute peripheral metabolic effects of intraarterial ghrelin infusion in healthy young men. The Journal of Clinical Endocrinology \& Metabolism, 96, 468 -477.

61. Thidarmyint, H., Yoshida, H., Ito, T. \& Kuwayama, H. 2006. Dose-dependent response of plasma ghrelin and growth hormone concentrations to bovine ghrelin in Holstein heifers. Journal of endocrinology, 189, 655 -664.

62. Sun, Y., Garcia, J. M. \& Smith, R. G. 2007. Ghrelin and growth hormone secretagogue receptor expression in mice during aging. Endocrinology, $148,1323-1329$.

63. Suchankova, G., Tekle, M., Saha, A. K., Ruderman, N. B., Clarke, S. D. \& Gettys, T. W. 2005. Dietary polyunsaturated fatty acids enhance hepatic AMP-activated protein kinase activity in rats. Biochemical and biophysical research communications, 326, $851-858$.

64. Watt, M. J., Steinberg, G. R., Chen, Z. P., Kemp, B. E. \& Febbraio, M. A. 2006. Fatty acids stimulate AMP-activated protein kinase and enhance fatty acid oxidation in L6 myotubes. The Journal of physiology, 574, 139 -147.

65. Zhang, X. Q., Xu, C. F., Yu, C. H., Chen, W. X. \& Li, Y. M. J. W. J. O. G. W. 2014 b. Role of endoplasmic reticulum stress in the pathogenesis of nonalcoholic fatty liver disease. 20, 1768.

66. Basseri, S. \& Austin, R. C. 2008. ER stress and lipogenesis: a slippery slope toward hepatic steatosis. Developmental cell, 15, 795 -796.

67. Seo, J., Fortuno, E. S., Suh, J. M., Stenesen, D., Tang, W., Parks, E. J., Adams, C. M., Townes, T. \& Graff, J. M. 2009. Atf4 regulates obesity, glucose homeostasis, and energy expenditure. Diabetes, 58, 2565 -2573.

68. Xiao, G., Zhang, T., Yu, S., Lee, S., Calabuig-Navarro, V., Yamauchi, J., Ringquist, S. \& Dong, H. H. 2013. ATF4 protein deficiency protects against high fructose-induced hypertriglyceridemia in mice. Journal of biological chemistry, 288, $25350-25361$.

69. Kim, I., Xu, W. \& Reed, J. C. 2008. Cell death and endoplasmic reticulum stress: disease relevance and therapeutic opportunities. Nature reviews Drug discovery, 7, $1013-1030$.

70. Yamamoto, K., Takahara, K., Oyadomari, S., Okada, T., Sato, T., Harada, A. \& Mori, K. 2010. Induction of liver steatosis and lipid droplet formation in ATF6a-knockout mice burdened with pharmacological endoplasmic reticulum stress. Molecular biology of the cell, 21, 2975 -2986.

71. Iwasaki, Y., Dezaki, K., Kumari, P., Kakei, M. \& Yada, T. 2015. Ghrelin counteracts insulin-induced activation of vagal afferent neurons via growth hormone secretagogue receptor. Neuropeptides, 52, 55 -60.

72. Chen, J. A., Splenser, A., Guillory, B., Luo, J., Mendiratta, M., Belinova, B., Halder, T., Zhang, G., Li, Y. P. \& Garcia, J. M. 2015. Ghrelin prevents tumour-and cisplatin-induced muscle wasting: characterization of multiple mechanisms involved. Journal of cachexia, sarcopenia and muscle, 6, 132 -143.

73. Guillory, B., Jawanmardi, N., lakova, P., Anderson, B., Zang, P., Timchenko, N. A. \& Garcia, J. M. 2018. Ghrelin deletion protects against age-associated hepatic steatosis by downregulating the C/EBPa-p300/DGAT1 pathway. Aging cell, 17, e12688. 